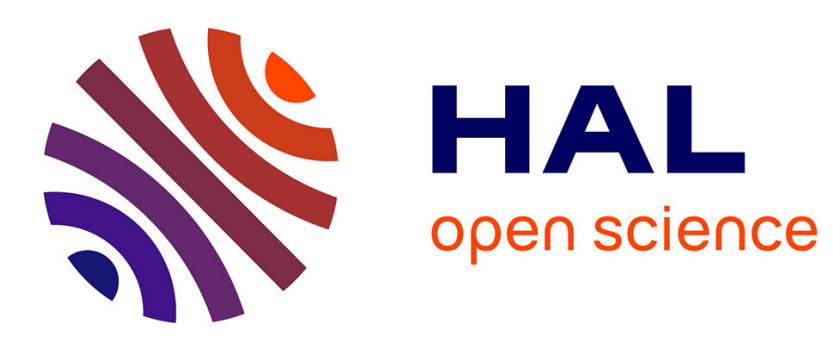

\title{
Application of osmolality for the determination of water activity and the modelling of cloud formation \\ G. Kiss, H.-C. Hansson
}

\section{To cite this version:}

G. Kiss, H.-C. Hansson. Application of osmolality for the determination of water activity and the modelling of cloud formation. Atmospheric Chemistry and Physics Discussions, 2004, 4 (6), pp.76677689. hal-00301511

\author{
HAL Id: hal-00301511 \\ https://hal.science/hal-00301511
}

Submitted on 24 Nov 2004

HAL is a multi-disciplinary open access archive for the deposit and dissemination of scientific research documents, whether they are published or not. The documents may come from teaching and research institutions in France or abroad, or from public or private research centers.
L'archive ouverte pluridisciplinaire $\mathbf{H A L}$, est destinée au dépôt et à la diffusion de documents scientifiques de niveau recherche, publiés ou non, émanant des établissements d'enseignement et de recherche français ou étrangers, des laboratoires publics ou privés. 


\section{Application of osmolality for the determination of water activity and the modelling of cloud formation}

\section{G. Kiss ${ }^{1,2}$ and H.-C. Hansson ${ }^{2}$}

${ }^{1}$ Air Chemistry Group of the Hungarian Academy of Sciences, University of Veszprém, P.O. Box 158, Veszprém, 8201, Hungary

${ }^{2}$ Institute of Applied Environmental Research, Stockholm University, Stockholm, 10691, Sweden

Received: 18 October 2004 - Accepted: 25 October 2004 - Published: 24 November 2004 Correspondence to: G. Kiss (kissgy @almos.vein.hu)

(c) 2004 Author(s). This work is licensed under a Creative Commons License.

\section{Osmolality-derived activity in cloud modelling \\ G. Kiss and \\ H.-C. Hansson}

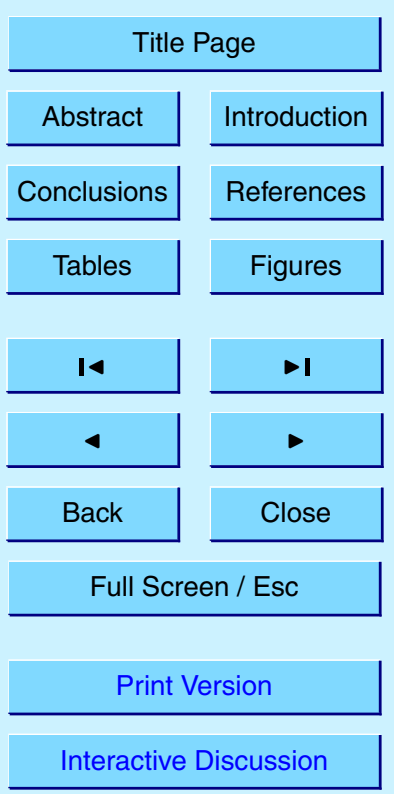




\section{Abstract}

A simple approach is suggested here to give reliable estimates on the Raoult term of the Köhler equation when calculating critical supersaturation $\left(S_{C}\right)$ for real atmospheric samples. Water activity is calculated from osmolality and thus the original Köhler equacan be applied avoiding the difficulties with unknown molecular weights, solubilities, van't Hoff factors of aerosol constituents and also the interactions in the growing droplet. First, water activity calculated from osmolality data was compared to literature values both for electrolytes and a non-electrolyte. Then the applicability of the approach was demonstrated by generating Köhler curves from osmolality derived and calculated with the osmolality approach fitted those obtained by using literature water activity data within a relative deviation of less than $0.3 \%, 0.8 \%, 1.1 \%$ and $3.4 \%$ for sucrose, $\mathrm{CaCl}_{2}, \mathrm{NaCl}$ and $\mathrm{H}_{2} \mathrm{SO}_{4}$, respectively, while the corresponding errors with the simplified Köhler equation were $11 \%, 8.5 \%, 4.5 \%$ and $19 \%$ in the dry nucleus size

15 range of $20 \mathrm{~nm}$ to $100 \mathrm{~nm}$. Finally, the osmolality method was used to show how considerably $S_{C}$ is underestimated for organic acids if complete dissociation is assumed.

The method described in this paper can be applied to real atmospheric samples (aerosol extracts, fog water or cloud water) thus improving the reliability of estimates on critical supersaturation and critical droplet diameter in atmospheric modelling.

\section{Introduction}

The sub-micron sized water-soluble particles in the atmosphere act as condensation sites for water in cloud formation. Only some grow to full size cloud droplets, i.e. they activate. The size and chemistry of a particle influence whether the particle will actually grow to cloud droplet. The chemistry and size of the atmospheric aerosol may then influence the radiation budget as well as the hydrological cycle (Ramanathan et al., 2001). However the magnitude of the radiative effect is not well known (IPCC report
ACPD

4, 7667-7689, 2004

\section{Osmolality-derived activity in cloud modelling}

G. Kiss and

H.-C. Hansson

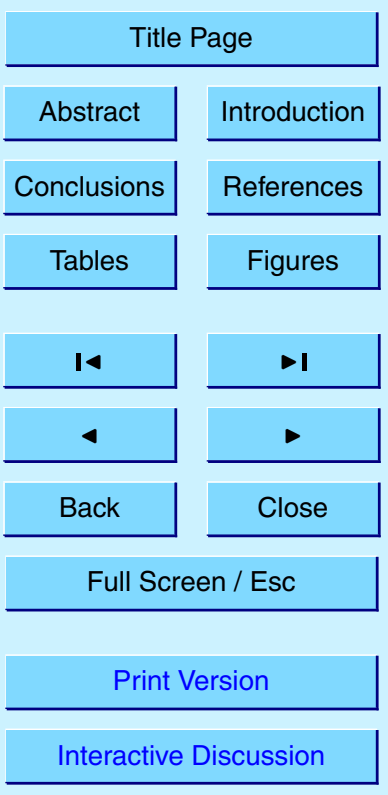

EGU 
2001). The uncertainty originates from the limited knowledge available on the physical, chemical and physico-chemical properties of aerosol particles, haze and cloud droplets and the cloud formation process itself.

Köhler theory (Köhler, 1936) is often used to model cloud formation and the Köhler 5 equation itself gives the equilibrium supersaturation (S) over a solution droplet of radius $r$ :

$\mathrm{S}=\mathrm{p} / \mathrm{p}_{0}-1=\mathrm{a}_{w} \exp \left[2 \sigma_{\text {solution }} \mathrm{M}_{w} /\left(\mathrm{r} \rho_{\text {water }} \mathrm{RT}\right)\right]-1$,

where $p$ is the water vapour pressure over the droplet, $p_{0}$ is the vapour pressure over a flat water surface, $a_{w}$ is the water activity in the droplet solution, $\sigma_{\text {solution }}$ is the surface 10 tension of the droplet solution, $\mathrm{M}_{w}$ is the molecular weight of water, $\rho_{\text {water }}$ is the density of water, $R$ is the universal gas constant and $T$ is the temperature.

In this equation $\mathrm{a}_{w}$ accounts for the vapour pressure decrease caused by the solutes dissolved in the droplet (also referred to as Raoult effect) while the vapour pressure increase due to the curvature of the droplet is considered in the exponential term (the 15 Kelvin term). By introducing the simplifications that the water activity coefficient equals 1 and $\ln \left(\mathrm{p} / \mathrm{p}_{0}\right)=S$ and replacing the mole fraction of the solute $\left(\mathrm{n}_{s} /\left(\mathrm{n}_{s}+\mathrm{n}_{w}\right)\right)$ with its mole ratio $\left(\mathrm{n}_{s} / \mathrm{n}_{w}\right)$ Eq. (1) can be transformed into the following form:

$\mathrm{S}=2 \sigma_{\text {solution }} \mathrm{M}_{w} /\left(\mathrm{r} \rho_{\text {water }} \mathrm{RT}\right)-3 \mathrm{n}_{s} \mathrm{M}_{w} /\left(4 \mathrm{r}^{3} \pi \rho_{\text {water }}\right)$,

where $\mathrm{n}_{s}$ is the number of moles of dissolved species present in the droplet. This simplified form is often used in model calculations, although the transformation involves the assumption that the droplet is an ideally dilute solution (Shulman et al., 1996; Cruz and Pandis, 1997, 1998; Li et al., 1998). It is an acceptable assumption except the initial phase of water condensation when the solution is far from being ideal. In some papers the osmotic coeffient $(\Phi)$ is inserted into the second (Raoult) term to account for non-ideality, however in most calculations it is set to 1 or another constant value due to the lack of appropriate data. Furthermore, it is known that the osmotic coefficient depends on concentration (Clegg et al., 1996).

ACPD

4, 7667-7689, 2004

Osmolality-derived activity in cloud modelling

G. Kiss and

H.-C. Hansson

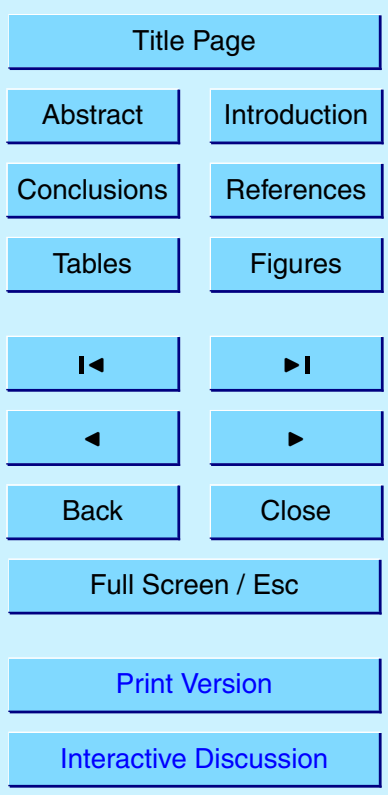

EGU 
Activation properties of dominant inorganic aerosol components (e.g. $\mathrm{NaCl}$, $\left.\left(\mathrm{NH}_{4}\right)_{2} \mathrm{SO}_{4}\right)$ have been studied in laboratory experiments with cloud condensation nuclei counter. A deviation of $-15 \%$ to $+37 \%$ was observed between experimental results and theoretical values calculated with the simplified Köhler equation (Cruz and Pandis, 5 1997; Kumar et al., 2003). The difference between theory and experiments was considerably less when the original Köhler equation (Eq. 1) was used and non-ideality of the ammonium sulphate solution was taken into account by using activity coefficients (Kumar et al., 2003).

Recently, it has been shown that in addition to inorganic salts organic aerosol compo10 nents play also role in cloud condensation (Novakov and Penner, 1993; Saxena et al., 1995; Novakov and Corrigan, 1996; Zappoli et al., 1999). However, while the inorganic content of the fine aerosol is dominated by a few ionic species, the carbonaceous matter is composed of thousands of organic compounds the majority of which is unknown. Thermal, spectroscopic and chromatographic techniques as well as mass spectrometry revealed that a significant fraction of the water-soluble organic carbon content in fine aerosol is included in a complex mixture of organic compounds similar to aquatic and terrestrial humic substances but having lower molecular weights (Krivácsy et al., 2001; Kiss et al., 2002, 2003). Such a complex organic mixture can be formed in the atmosphere from both anthropogenic and natural precursors (Gelencsér et al., 2002, 2003; Limbeck et al., 2003; Hoffer et al., 2004; Kalberer et al., 2004) and makes Köhler model calculations very complicated. Surface tension measurements in cloud and fog water (Hitzenberger et al., 2002; Facchini et al., 2000) as well as aqueous aerosol extracts (Facchini et al., 2000; Kiss et al., 2004) give some hints on the effect of organic aerosol constituents on the Kelvin term although the possible partitioning of organic surfactants between the bulk droplet solution and the droplet surface should also be considered to get more reliable estimates (Sorjamaa et al., 2004). The estimation of the Raoult term seems to be more difficult. In this case either water activity $\left(a_{w}\right.$ in Eq. 1) or the number of dissolved moles ( $\mathrm{n}_{s}$ in Eq. 2) has to be known. The second approach is usually applied and thus $\mathrm{n}_{s}$ is extended to include both organic and inorganic aerosol

ACPD

4, 7667-7689, 2004

\section{Osmolality-derived activity in cloud modelling}

G. Kiss and

H.-C. Hansson

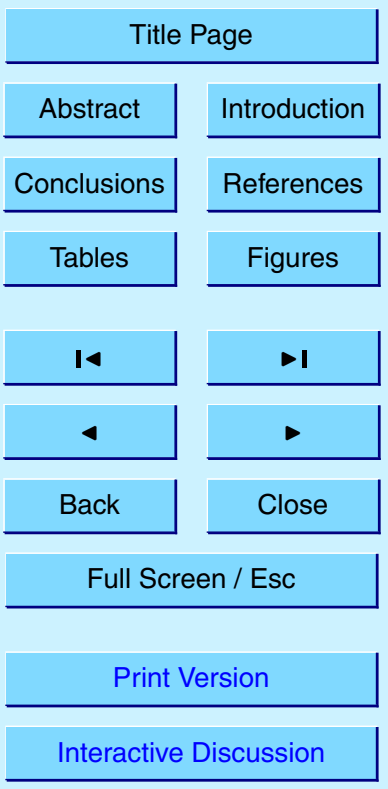

EGU 
components:

$\mathrm{n}_{s}=\mathrm{n}_{\text {org }}+\mathrm{n}_{\text {inorg }}=\Sigma \mathrm{i}_{j, \text { org }} * \mathrm{~m}_{j, \text { org }} / \mathrm{MW}_{j, \text { org }}+\Sigma \mathrm{i}_{k, \text { inorg }} * \mathrm{~m}_{k, \text { inorg }} / \mathrm{MW}_{k, \text { inorg}}$,

where $\mathrm{n}_{\text {org }}$ and $\mathrm{n}_{\text {inorg }}$ are the number of dissolved species originating from organic and inorganic aerosol components, respectively; $i_{j, \text { org }}$ and $i_{k, i n o r g}$ are van't Hoff factors

5 of the j-th organic and k-th inorganic components, respectively; $\mathrm{m}_{j, o r g}$ and $\mathrm{m}_{k, i n o r g}$ are the mass of the $j$-th organic and k-th inorganic components, respectively, dissolved in the growing droplet; $\mathrm{MW}_{j, \text { org }}$ and $\mathrm{MW}_{k, \text { inorg }}$ are the molecular weights of the $\mathrm{j}$-th organic and k-th inorganic components, respectively.

In order to calculate $\mathrm{n}_{s}$ according to Eq. (3) the solubility, the molecular weight and

10 the dissociation properties of both the organic and inorganic compounds should be known, which is not at all the case in real atmospheric samples. Not even all compounds are known. In addition, the concentration of the organic and inorganic aerosol components varies during droplet growth resulting in changing van't Hoff factors. Since it is difficult to appropriately describe such a complex mixture, the organic aerosol content is simplified to model compounds (typically organic acids) with known or hypothetical properties. This simplification is helpful in developing a better theoretical understanding of these processes. However, when used to establish the magnitude of the effect it is necessary to calculate or measure on the actual mixture of compounds. Using not validated simplifications either in calculations or measurements introduces an error of unknown magnitude into the Köhler equation hindering the correct estimation of the effect of organic aerosol components on critical supersaturation. Even if MW and $m$ are available for an organic model compound the dissociation behaviour during droplet growth has to be considered carefully. It is often assumed, for example, that $i=2$ or $\mathrm{i}=3$ for dicarboxylic acids which means high degree of dissociation. However, it can 25 be calculated by using dissociation constants at the concentration and $\mathrm{pH}$ conditions relevant in cloud droplet formation that van't Hoff factors are close to 1 (see details in Sect. 2 and also in Kumar et al., 2003). In addition, the presence of inorganic salt (e.g. ammonium sulphate) in the droplet further suppresses the dissociation of organic acids (salting out effect).

Osmolality-derived activity in cloud modelling

G. Kiss and

H.-C. Hansson

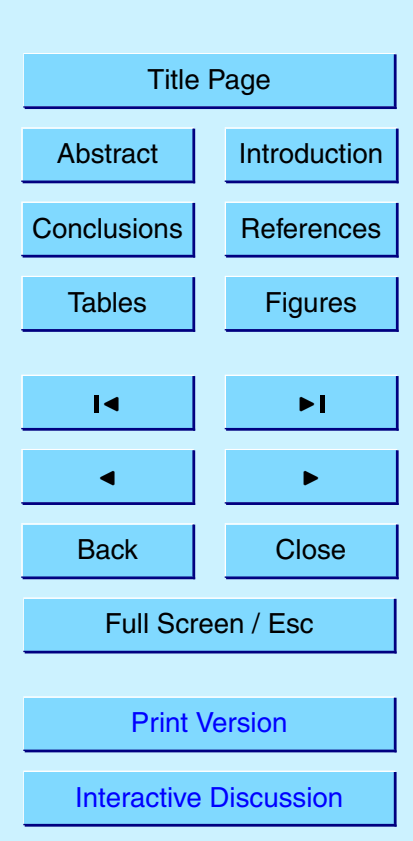

EGU 
It is not straightforward either to calculate the van't Hoff factor of inorganic aerosol components. Typically, $\mathrm{i}=2$ and $\mathrm{i}=3$ is used for $\mathrm{NaCl}$ and $(\mathrm{NH} 4)_{2} \mathrm{SO}_{4}$, respectively, assuming complete dissociation and no interactions in aqueous solutions. However, in electrolyte solutions there are electrostatic interactions between the charged cations 5 and anions (Denbigh, 1981) leading to lower $i$ values than the maximum number of ions that can potentially be formed from one salt molecule. These interactions are present in the solution of highly water-soluble electrolytes as well, especially if the electrolyte consists of bivalent or trivalent ion. Young and Warren (1992) compiled earlier theoretical data and showed that the van't Hoff factor of ammonium sulphate 10 reaches 3 only if the solution is as dilute as $10^{-5}$ molal. In the concentration range that is relevant for cloud formation (approximately 0.01 to 1 molal) i varies between 1.9 and 2.6 which means that the magnitude of the Raoult term is overestimated by $15-58 \%$ when $\mathrm{i}=3$ is assumed.

The above-mentioned problems connected to the estimation of the Raoult effect in15 dicates that there is a strong need for another approach. All the uncertainties caused by the lack of knowledge on the

1. dissociation behaviour of organic and inorganic compounds as a function of concentration

2. solubility of organic compounds as a function of concentration of inorganic salts and other organic compounds

3. molecular weight of real organic aerosol constituents

can be eliminated if the water activity in the droplet is known and thus Eq. (1) can be used. Further advantage of the use of Eq. (1) is that the assumptions applied to achieve the simplified Köhler equation (Eq. 2) can also be omitted. In this paper we propose an approach to overcome the problems with the estimation of Raoult effect of real atmospheric solutions (i.e. complex mixture of inorganic and organic components). We suggest calculating water activity from osmolality thus avoiding the difficulties with
ACPD

4, 7667-7689, 2004

Osmolality-derived activity in cloud modelling

G. Kiss and

H.-C. Hansson

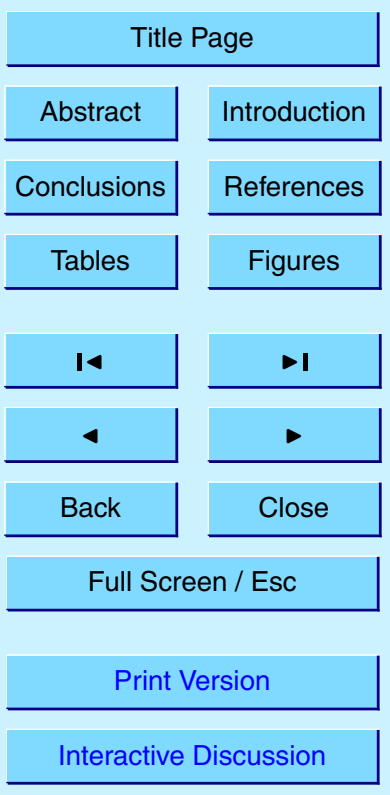


unknown molecular weights, solubilities, van't Hoff factors of aerosol constituents and also the interactions in the growing droplet. First, water activity calculated from osmolality data are compared to literature values both for electrolytes and a non-electrolyte. Then Köhler curves are calculated from osmolality derived and literature activity data 5 as well as by using the simplified Köhler equation to examine the difference originating from different approaches. Finally, $S_{c}$ is shown to be considerably underestimated for organic acids if complete dissociation is assumed. This error can be eliminated by using osmolality derived water activity as discussed below.

\section{Results and discussion}

\subsection{Comparison of osmolality derived water activity to literature values}

Water vapour pressure of an ideal solution can be calculated from the mole fraction of water in the solution (Raoult law). However, in a real solution intermolecular and electrostatic interactions occur and therefore the mole fraction has to be replaced by water activity to calculate water vapour pressure. Since activity accounts for these interactions it is also defined as the "effective" mole fraction (Atkins, 1995). Water activity can be determined by a number of techniques such as vapour pressure measurement, freezing point depression, osmotic pressure measurement (Denbigh, 1981). Freezing point depression and osmotic pressure can also be expressed in terms of osmolality (Kiyosawa, 2003). By definition, the osmolality of a solution gives the number of moles of osmotically active species in one $\mathrm{kg}$ of water. Since osmolality $\left(\mathrm{C}_{\text {osm }}\right)$ accounts for all processes in the solution (e.g. dissociation, electrostatic and intermolecular interactions) that influence vapour pressure it can be used for the calculation of the "effective" mole fraction of water, i.e. the approximation of activity:

$\mathrm{a}_{w}=1000 / \mathrm{MW}_{\text {water }} /\left(1000 / \mathrm{MW}_{\text {water }}+\mathrm{C}_{\text {osm }}\right)$,

25 where $\mathrm{MW}_{\text {water }}$ is the molecular weight of water and $\mathrm{C}_{\text {osm }}$ is expressed in Osmol kg-1.
ACPD

4, 7667-7689, 2004

Osmolality-derived activity in cloud modelling

G. Kiss and

H.-C. Hansson

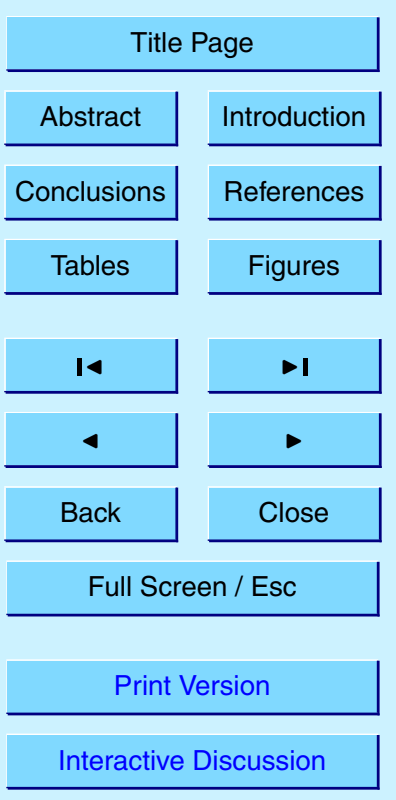

EGU 
To test the validity of Eq. (4) osmolality derived water activity data were compared to literature values. Compounds with osmolality and water activity data available in a wide concentration range were needed to perform this comparison. Furthermore, Eq. (4) had to be tested on both electrolytes and non-electrolytes since both types of 5 compounds are present in atmospheric aerosol. The only organic compound for which both water activity and parallel osmolality data were found is sucrose. Consequently, it was selected as a non-electrolyte test compound and inorganic salts were chosen as electrolyte test compounds. Since electrolytes always deviate more from ideality than non-electrolytes, three different types of the latter were selected for the study: 10 sodium chloride (consisting of a monovalent cation and a monovalent anion), calcium chloride (consisting of a bivalent cation and two monovalent anions) and sulphuric acid (consisting of two monovalent cation and a bivalent anion). Water activity data in a wide concentration range are available for these four compounds (Robinson and Stokes, 1965) while osmolality data were taken from Weast (1988).

15 Osmolality derived water activity data (using Eq. 4) are compared to literature values for all four compounds in Fig. 1. It can be seen that in the whole examined concentration range water activity data of sucrose (the non-electrolyte test compound) derived from its osmolality are practically identical to the literature values. Furthermore, only a slight difference was observed for the three electrolytes independently of the size

charge of the ion components and the deviation from ideal behaviour. An additional comparison was done with ammonium sulphate at a molality of $1.054 \mathrm{~mol} \mathrm{~kg}^{-1}$. Clegg et al. (1996) compared water activity data from direct vapour pressure determinations with model predictions at the above concentration in a wide temperature range $\left(32-100^{\circ} \mathrm{C}\right)$. At this concentration no temperature dependence was observed between 2532 and $70^{\circ} \mathrm{C}$ and the experimental water activity data scattered mostly in the 0.9640 and 0.9690 range including the predicted value of 0.9645 . By using Eq. (4) and osmolality data from Weast (1988) water activity of 0.9668 is obtained, which is in good agreement both with the experimental results and the model predictions.
ACPD

4, 7667-7689, 2004

\section{Osmolality-derived activity in cloud modelling}

G. Kiss and

H.-C. Hansson

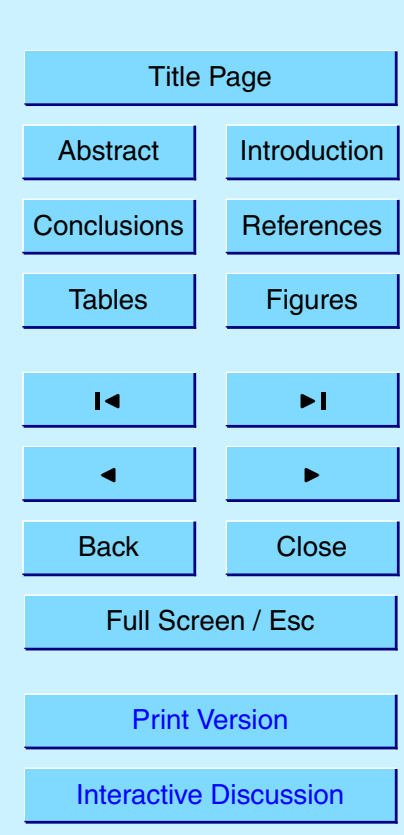


Since the objective of the study was the application of osmometry in Köhler model calculations, Köhler curves obtained with different approaches were compared. Since Eq. (1) does not involve simplifications, the Köhler curve generated by substituting 5 activity data in it is supposed to be closest to reality. Köhler curves obtained for sucrose by substituting osmolality derived and literature activity data in Eq. (1) as well as using the simplified Köhler equation (Eq. 2) are compared in Fig. 2. The following conditions were applied:

$\sigma_{\text {solution }}=\sigma_{\text {water }}=0.07273 \mathrm{~N} \mathrm{~m}^{-1}, \mathrm{M}_{w}=0.01802 \mathrm{~kg} \mathrm{~mol}^{-1}, \rho_{\text {water }}=998.21 \mathrm{~kg} \mathrm{~m}^{-3}$,

$10 \mathrm{R}=8.314 \mathrm{~J} \mathrm{~mol}^{-1} \mathrm{~K}^{-1}, \mathrm{~T}=293.15 \mathrm{~K}, \mathrm{MW}_{\text {sucrose }}=0.3423 \mathrm{~kg} \mathrm{~mol}^{-1}, \mathrm{i}_{\text {sucrose }}=1$.

The Köhler curves of sucrose with a dry nucleus diameter of $40 \mathrm{~nm}$ and $100 \mathrm{~nm}$ are shown in Fig. $2 a$ and b, respectively. The curves created by substituting osmolality derived or literature water activity data into Eq. (1) resulted in practically identical critical supersaturation $\left(S_{C}\right)$ values while the simplified Köhler equation overestimated $S_{c}$ by

$151.7 \%$ and $5.1 \%$ for a dry nucleus of $100 \mathrm{~nm}$ and $40 \mathrm{~nm}$, respectively. This deviation is even more pronounced for a dry nucleus of $20 \mathrm{~nm}$ and originates from the non-ideality of the sucrose solution. As it is shown in Table 1 the critical diameter to dry diameter ratio decreases with decreasing diameter of dry nucleus. Consequently, the droplet solution around the critical diameter is more concentrated with smaller particles. For example, the molality of the sucrose solution in a droplet corresponding to the critical size of a dry nucleus of $20 \mathrm{~nm}$ and $100 \mathrm{~nm}$ are $0.777 \mathrm{~mol} \mathrm{~kg}^{-1}(21 \mathrm{w} / \mathrm{w} \%)$ and $0.106 \mathrm{~mol}$ $\mathrm{kg}^{-1}(3.5 \mathrm{w} / \mathrm{w} \%)$, respectively. The former solution significantly deviates from ideal behaviour and the simplified Köhler equation does not take it into account while it is considered in Eq. (1) with the osmolality derived activities. As the size of the dry nucleus increases, the $S_{c}$ values calculated with the simplified curve approach those obtained with the other two curves. Concerning the critical droplet diameter $\left(\mathrm{d}_{c}\right)$, it is underestimated by $4-20 \%$ with the simplified Köhler equation while it is obtained exactly with osmolality derived water activities.

\section{Osmolality-derived activity in cloud modelling}

G. Kiss and

H.-C. Hansson

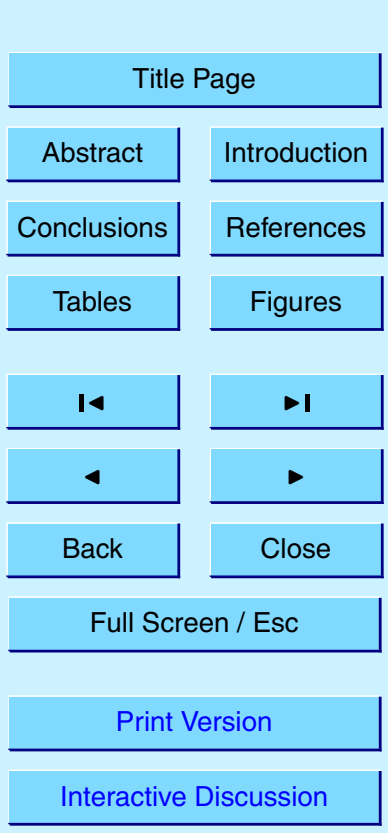

EGU 
Next, the applicability of Eq. (4) is demonstrated on the three electrolytes mentioned above. The curves created for $\mathrm{NaCl}$ by substituting osmolality derived or literature water activity data into Eq. (1) resulted in almost identical critical supersaturation $\left(\mathrm{S}_{c}\right)$ values (with a relative deviation less than $1 \%$ ) while the simplified Köhler equation 5 underestimated $\mathrm{S}_{c}$ by $4-4.5 \%$ independently of the size of the dry nucleus as quantified in Table 2. The reason of this deviation is the non-ideality of the solution again. As a consequence of electrostatic interactions in the solution the van't Hoff factor of $\mathrm{NaCl}$ is less than 2 even in dilute solutions. Therefore the magnitude of the Raoult term is overestimated with the simplified Köhler equation leading to the underestimation of $S_{c}$. 10 Concerning the critical droplet diameter $\left(d_{c}\right)$, it is overestimated by $3.5-6 \%$ with the simplified Köhler equation while the same values are obtained with osmolality derived and literature water activities.

A significant increase in the error of prediction of $S_{C}$ can be observed with the simplified Köhler equation when double charged ions (like $\mathrm{Ca}^{2+}$ or $\mathrm{SO}_{4}^{2-}$ ) are present in 15 the solution while the osmolality derived activity values yield similarly good estimates. The results for $\mathrm{CaCl}_{2}$ are summarized in Table 3. The deviation of $\mathrm{S}_{C}$ obtained by substituting osmolality derived water activity into Eq. (1) was less than $0.8 \%$ in the whole size range while the simplified form (Eq. 2) systematically underestimated $S_{C}$ by about $8 \%$. The critical droplet diameter was exactly obtained with the former approach (except dry nucleus of $20 \mathrm{~nm}$ where a relative deviation of $-3 \%$ was observed), however the simplified form overestimated $d_{c}$ by $5-9 \%$. The largest difference was obtained with sulphuric acid as shown in Table 4, Fig. $3 a$ and b. In this case the $S_{c}$ values obtained by substituting osmolality derived water activity deviated by $-1.2 \%$ to -3.4 $\%$ from the $S_{c}$ values achieved by applying literature activity data while a relative deviation of $-1.2 \%$ to $+2.6 \%$ was observed in $d_{c}$. However, the simplified form (Eq. 2) systematically underestimated $S_{C}$ by $18-19 \%$ and overestimated $d_{c}$ by $20-23 \%$ ! The significantly higher error experienced with the latter two electrolytes can be explained with the presence of bivalent ions. The higher the charge of the ions, the stronger electrostatic interactions occur in the solution. Consequently, the van't Hoff factor of

ACPD

4, 7667-7689, 2004

\section{Osmolality-derived activity in cloud modelling}

G. Kiss and

H.-C. Hansson

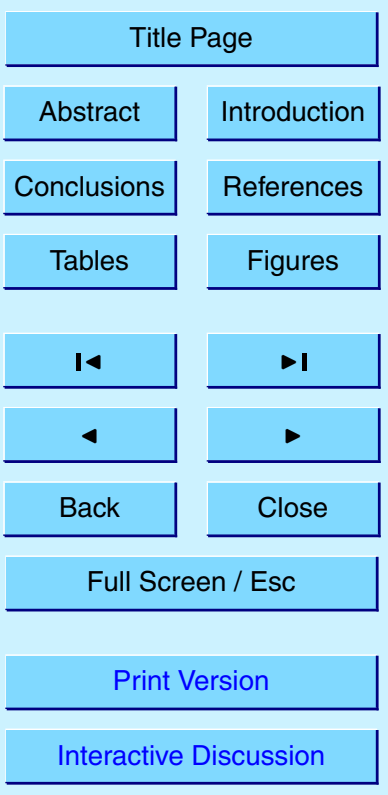


$\mathrm{CaCl}_{2}$ and $\mathrm{H}_{2} \mathrm{SO}_{4}$ deviates significantly from 3. Furthermore, in case of $\mathrm{H}_{2} \mathrm{SO}_{4}$ not only the electrostatic interactions but also the incomplete dissociation must be taken into account. Sulphuric acid is a strong acid and therefore in dilute solutions the acid molecule dissociates practically completely into a proton and a hydrogen-sulphate ion. 5 However, the hydrogen-sulphate ion is by far not as strong acid as the acid molecule and its dissociation constants equals only 0.012 (Weast, 1988). Consequently, in a solution of $0.1 \mathrm{~mol} \mathrm{~kg}^{-1}$ about $90 \%$ of the acid can be found in $\mathrm{HSO}_{4}^{-}$form and only $10 \%$ in $\mathrm{SO}_{4}^{2-}$ form resulting in a van't Hoff factor of 2.1 instead of 3 . This means that the magnitude of the Raoult term is overestimated by more than $40 \%$ in the simplified Köhler equation (if $i=3$ is assumed) and explains why the $S_{c}$ of sulphuric acid is underestimated to such a high extent.

2.3. Application of the osmolality derived water activity to calculate the Köhler curve of organic acids

The incomplete dissociation has even more pronounced effect on the van't Hoff factor of

a solution of e.g. $0.1 \mathrm{~mol} \mathrm{~kg}^{-1}$ the van't Hoff factors of oxalic acid (C2 dicarboxylic acid), malonic acid (C3 dicarboxylic acid), succinic acid (C4 dicarboxylic acid) and citric acid (C6 tricarboxylic acid) are 1.53, 1.11, 1.03 and 1.08, respectively. These figures clearly show that the van't Hoff factor of organic acids is substantially less than the number of ions that can potentially be formed from a molecule. As a consequence, van't Hoff factors close to unity should be used for weak organic acids in model calculations as also applied by Bilde and Svenningsson (2004). The magnitude of the Raoult term is overestimated by a factor of 2 to 4 if complete dissociation is assumed for di- and tricarboxylic acids in Eq. (3) resulting in a substantial underestimation of $S_{c}$. As an example, Köhler curves for citric acid particles having dry nucleus of $40 \mathrm{~nm}$ and $100 \mathrm{~nm}$ are shown in Fig. 4a and b, respectively. Independently of the dry nucleus diameter $\mathrm{S}_{C}$ is slightly $(4 \%)$ overestimated by substituting $\mathrm{i}=1$ into the simplified formula and

ACPD

4, 7667-7689, 2004

\section{Osmolality-derived activity in cloud modelling}

G. Kiss and

H.-C. Hansson

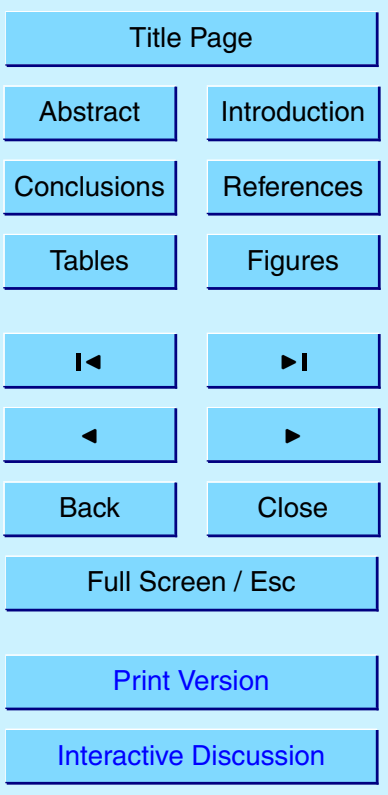

EGU 
significantly (26-48\%) underestimated when $i=2-4$ is applied. This deviation is caused again by the incomplete dissociation of citric acid and the electrostatic interactions in the solution. The error in $S_{c}$ estimates obtained by the simplified formula can be even larger for polyacids with unknown molecular weights and dissociation constants while 5 these uncertainties can be eliminated by using the osmolality derived activity approach suggested here.

On the basis of the comparison in Tables 1-4 it can be concluded that original Köhler equation using osmolality derived water activity gave significantly better estimates on $\mathrm{S}_{c}$ and $\mathrm{d}_{c}$ than the simplified Köhler equation. Water activity can precisely be obtained 10 from osmolality since the typical working range of an osmometer (ca. 3 orders of magnitude) is transformed into the water activity range of $0.9-1.0$ by applying Eq. (4). Further advantage of the osmolality derived activity is that it can be easily determined for solutions containing complex mixtures of organic and inorganic components with unknown solubility, molecular weight and van't Hoff factors while the simplified Köhler formula cannot be applied in such cases. By measuring the osmolality of real atmospheric samples (aerosol extracts, fog water or cloud water) and using the approach discussed above the reliability of estimates on critical supersaturation and critical droplet diameter can be improved significantly.

Acknowledgements. The Marie Curie Individual Fellowship of the European Commission (Con20 tract No. HPMF-CT-2002-01647) and the Nordic Center of Excellence in Biosphere-AerosolCloud-Climate Interactions (BACCl) are gratefully acknowledged for support.

\section{References}

Atkins, P. W.: Physical Chemistry, Oxford University Press, Oxford, 1995.

Bilde, M. and Svenningsson, B.: CCN activation of slightly soluble organics: the importance of small amounts of inorganic salt and particle phase, Tellus, 56B, 128-134, 2004.

Clegg, S. L., Milioto, S., and Palmer, D. A.: Osmotic and activity coefficients of aqueous

\section{Osmolality-derived activity in cloud modelling}

G. Kiss and

H.-C. Hansson

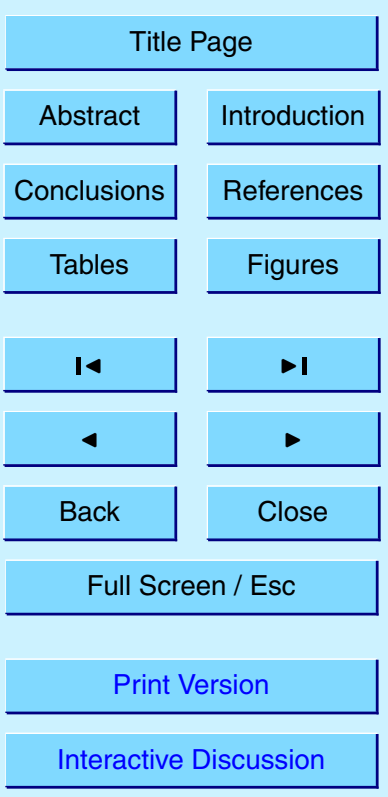


$\left(\mathrm{NH}_{4}\right)_{2} \mathrm{SO}_{4}$ as a function of temperature, and aqueous $\left(\mathrm{NH}_{4}\right)_{2} \mathrm{SO}_{4}-\mathrm{H}_{2} \mathrm{SO}_{4}$ mixtures at 298.15 $\mathrm{K}$ and $323.15 \mathrm{~K}$, J. Chem. Eng. Data, 41, 455-467, 1996.

Cruz, C. and Pandis, S. N.: The effect of organic coatings on the cloud condensation nuclei activation of inorganic atmospheric aerosol, J. Geophys. Res., 103 (D11), 13111-13123, 1988.

Cruz, C. and Pandis, S. N.: A study of the ability of pure secondary organic aerosol to act as cloud condensation nuclei, Atmos. Envir., 31, 2205-2214, 1997.

Denbigh, K.: The principles of chemical equilibrium, Cambridge University Press, Cambridge, 1981.

10 Facchini, M. C., Decesari, S., Mircea, M., Fuzzi, S., and Loglio, G.: Surface tension of atmospheric wet aerosol and cloud/fog droplets in relation to their organic carbon content and chemical composition, Atmos. Envir., 34, 4853-4857, 2000.

Gelencsér, A., Hoffer, A., Krivácsy, Z., Kiss, G., Molnár, Á., and Mészáros, E.: On the possible origin of humic matter in fine continental aerosol, J. Geophys. Res. 107, 4137, 15 doi:10.1029/2001JD001299, 2002.

Gelencsér, A., Hoffer, A., Kiss, G., Tombácz, E., Krudi, R., and Bencze, L.: In-situ formation of light-absorbing organic matter in cloud water, J. Atmos. Chem., 45, 25-33, 2003.

Hitzenberger, R., Berner, A., Kasper-Giebl, A., Loflund, M., and Puxbaum, H.: Surface tension of Rax cloud water and its relation to the concentration of organic material, J. Geophys. Res., $20 \quad$ 107, 4752, doi:10.2029/2002JD002506, 2002.

Hoffer, A., Kiss, G., Blazsó, M., and Gelencsér, A.: Chemical characterization of humic-like substances (HULIS) formed from a lignin-type precursor in model cloud water, Geophys. Res. Lett., 31, L06115, doi:10.1029/2003GL018962, 2004.

Intergovernmental Panel on Climate Change: Third assessment report, http://www.ipcc.ch, 2001.

Kalberer, M., Paulsen, D., Sax, M., Steinbacher, M., Dommen, J., Prevot, A. S. H., Fisseha, R., Weingartner, E., Frankevich, V., Zenobi, R., and Baltensperger, U.: Identification of Polymers as Major Components of Atmospheric Organic Aerosols, Science, 303, 1659-1662, 2004.

Kiss, G., Varga, B., Galambos, I., and Ganszky, I.: Characterization of water-soluble organic matter isolated from atmospheric fine aerosol, J. Geophys. Res., 107, 8339, doi:10.1029/2001JD000603, 2002.

Kiss, G., Tombácz, E., Varga, B., Alsberg, T., and Persson, L.: Estimation of the average molecular weight of humic-like substances isolated from fine atmospheric aerosol, Atmos.

\section{Osmolality-derived activity in cloud modelling}

G. Kiss and

H.-C. Hansson

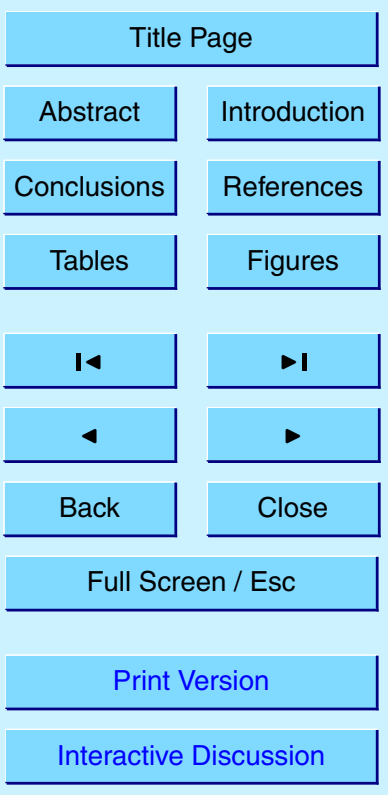

EGU 
Envir. 37, 3783-3794, 2003.

Kiss, G., Tombácz, E., and Hansson, H.-C.: Surface tension effects of humic-like substances in the aqueous extract of tropospheric fine aerosol, J. Atmos. Chem., accepted, 2004.

Kiyosawa, K.: Theoretical and experimental studies on freezing point depression and vapor 5 pressure deficit as methods to measure osmotic pressure of aqueous polyethylene glycol and bovine serum albumin solutions, Biophysical Chemistry, 104, 171-188, 2003.

Krivácsy, Z., Gelencsér, A., Kiss, G., Mészáros, E., Molnár, Á., Hoffer, A., Mészáros, T., Sárvári, Zs., Temesi, D., Varga, B., Baltensperger, U., Nyeki, S., and Weingartner, E.: Study on the chemical character of water soluble organic compounds in fine atmospheric aerosol at the Jungfraujoch, J. Atmos. Chem., 39, 235-259, 2001.

Kumar, P. P., Broekhuizen, K., and Abbatt, J. P. D.: Organic acids as cloud condensation nuclei: Laboratory studies of highly soluble and insoluble species, Atmos. Chem. Phys., 3, 509-520, 2003 ,

SRef-ID: 1680-7324/acp/2003-3-509.

Li, Y., Williams, A. L., and Rood, M. J.: Influence of soluble surfactant properties on the activation of aerosol particles containing inorganic solute, J. Atm. Sci., 55, 1859-1866, 1998.

Limbeck, A., Kulmala, M., and Puxbaum, H.: Secondary organic aerosol formation in the atmosphere via heterogeneous reaction of gaseous isoprene on acidic particles, Geophys. Res. Lett., 30, art. no. 1996, 2003.

20 Novakov, T. and Corrigan, C. E.: Cloud condensation nucleus activity of the organic component of biomass smoke particles, Geophys. Res. Lett., 23, 2141-2144, 1996.

Novakov, T. and Penner, J. E.: Large contribution of organic aerosols to cloud-condensationnuclei concentrations, Nature, 365, 823-826, 1993.

Ramanathan, V., Crutzen, P. J., Kiehl, J. T., and Rosenfeld, D.: Aerosols, Climate, and the Hydrological Cycle, Science, 294, 2119-2124, 2001.

Robinson, R. A. and Stokes, R. H.: Electrolyte solutions, Butterworths Publications, London, 1965.

Saxena P., Hildemann, L. M., McMurry, P. H., and Seinfeld, J. H.: Organics alter hygroscopic behaviour of atmospheric particles, J. Geophys. Res., 100, 18755-18770, 1995.

so Shulman, M. L., Jacobson, M. C., Charlson, R. J., Synovec, R. E., and Young, T. E.: Dissolution behavior and surface tension effects of organic compounds in nucleating cloud droplets, Geophys. Res. Lett., 23, 277-280, 1996.

Sorjamaa, R., Raatikainen, T., and Laaksonen, A.: The role of surfactants in Köhler theory

\section{ACPD}

4, 7667-7689, 2004

\section{Osmolality-derived activity in cloud modelling}

G. Kiss and

H.-C. Hansson

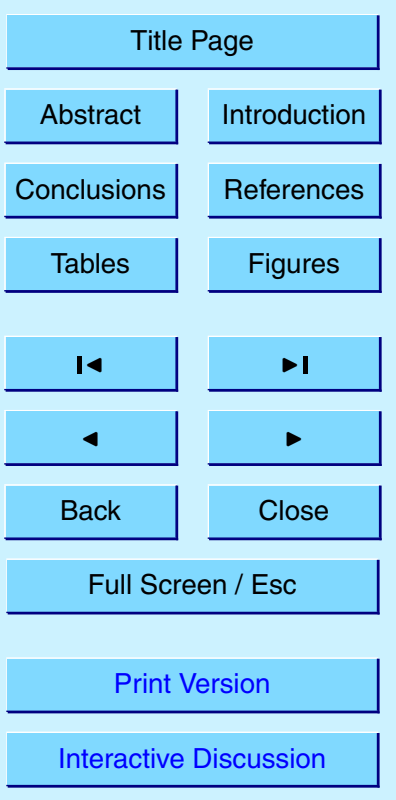

EGU 
reconsidered, Atmos. Chem. Phys. Discuss., 4, 2781-2804, 2004, SRef-ID: 1680-7375/acpd/2004-4-2781.

Weast, R. C.: CRC Handbook of Chemistry and Physics, 69th edition, CRC Press, Boca Raton, Florida, 1988.

5 Young, K. C. and Warren, A. J.: A reexamination of the derivation of the equilibrium supersaturation curve for soluble particles, J. Atmos. Sci., 49, 1138-1143, 1992.

\section{ACPD}

4, 7667-7689, 2004

\section{Osmolality-derived} activity in cloud modelling

G. Kiss and

H.-C. Hansson

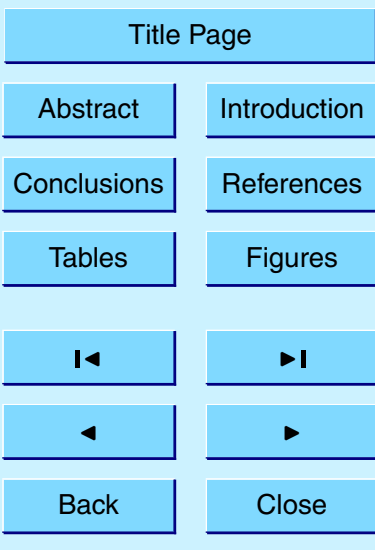

Full Screen / Esc

Print Version

Interactive Discussion 


\section{ACPD}

4, 7667-7689, 2004

\section{Osmolality-derived activity in cloud modelling}

Table 1. The critical supersaturation $\left(\mathrm{S}_{c}\right)$ and critical droplet diameter $\left(\mathrm{d}_{c}\right)$ obtained by using the original Köhler equation with literature water activities (2th-3th columns), osmolality derived water activities (5th-6th columns) and derived from the simplified Köhler equation (7th-8th columns) for sucrose particles of different dry diameters $\left(\mathrm{d}_{d r y}\right)$.

Non-simplified Köhler equation Non-simplified Köhler equation Simplified Köhler $a_{w}$ from literature equation $(\mathrm{i}=1)$

\begin{tabular}{cccccccc}
\hline $\mathrm{d}_{d r y}(\mathrm{~nm})$ & $\mathrm{S}_{c}(\%)$ & $\mathrm{d}_{c}(\mathrm{~nm})$ & $\mathrm{d}_{c} / \mathrm{d}_{d r y}$ & $\mathrm{~S}_{c}(\%)$ & $\mathrm{d}_{c}(\mathrm{~nm})$ & $\mathrm{S}_{c}(\%)$ & $\mathrm{d}_{c}(\mathrm{~nm})$ \\
\hline 20 & 4.22 & 38.2 & 1.91 & 4.21 & 38.2 & 4.70 & 30.6 \\
40 & 1.58 & 96.2 & 2.41 & 1.58 & 96.2 & 1.66 & 86.4 \\
70 & 0.700 & 211 & 3.01 & 0.700 & 211 & 0.718 & 200 \\
100 & 0.414 & 356 & 3.56 & 0.413 & 356 & 0.421 & 342 \\
\hline
\end{tabular}

G. Kiss and

H.-C. Hansson

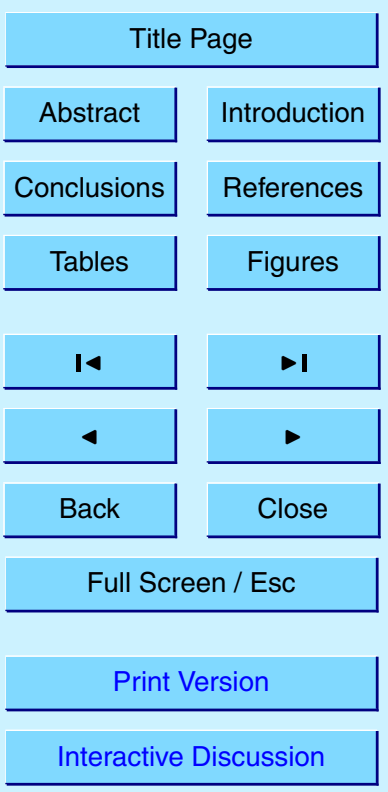




\section{ACPD}

4, 7667-7689, 2004

\section{Osmolality-derived activity in cloud modelling}

Table 2. The critical supersaturation $\left(\mathrm{S}_{c}\right)$ and critical droplet diameter $\left(\mathrm{d}_{c}\right)$ obtained by using the original Köhler equation with literature water activities (2th-3th columns), osmolality derived water activities (5th-6th columns) and derived from the simplified Köhler equation (7th-8th columns) for sodium chloride particles of different dry diameters $\left(\mathrm{d}_{d r y}\right)$.

\begin{tabular}{cccccccc}
\hline & \multicolumn{2}{c}{$\begin{array}{c}\text { Non-simplified Köhler equation } \\
\mathrm{a}_{w} \text { from literature }\end{array}$} & \multicolumn{2}{c}{$\begin{array}{c}\text { Non-simplified Köhler equation } \\
\mathrm{a}_{w} \text { from osmolality }\end{array}$} & \multicolumn{2}{c}{$\begin{array}{c}\text { Simplified Köhler } \\
\text { equation (i=2) }\end{array}$} \\
\hline $\mathrm{d}_{d r y}(\mathrm{~nm})$ & $\mathrm{S}_{c}(\%)$ & $\mathrm{d}_{c}(\mathrm{~nm})$ & $\mathrm{d}_{c} / \mathrm{d}_{d r y}$ & $\mathrm{~S}_{c}(\%)$ & $\mathrm{d}_{c}(\mathrm{~nm})$ & $\mathrm{S}_{c}(\%)$ & $\mathrm{d}_{c}(\mathrm{~nm})$ \\
\hline 20 & 1.23 & 116 & 5.81 & 1.23 & 116 & 1.18 & 122 \\
40 & 0.434 & 326 & 8.16 & 0.432 & 326 & 0.416 & 345 \\
70 & 0.188 & 768 & 11.0 & 0.186 & 768 & 0.180 & 799 \\
100 & 0.110 & 1318 & 13.2 & 0.109 & 1318 & 0.105 & 1365 \\
\hline
\end{tabular}

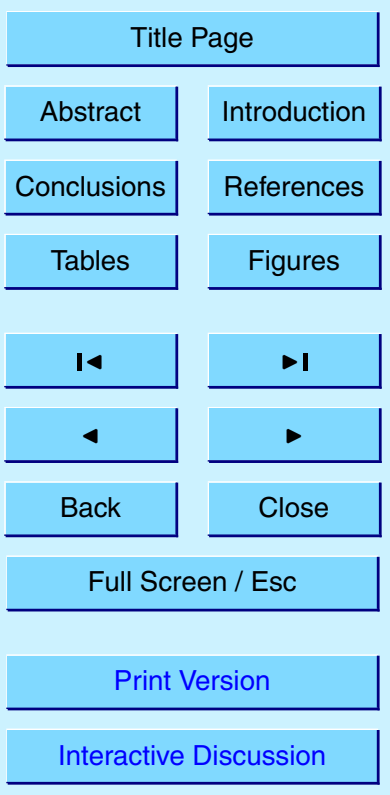




\section{ACPD}

4, 7667-7689, 2004

\section{Osmolality-derived activity in cloud modelling}

Table 3. The critical supersaturation $\left(\mathrm{S}_{c}\right)$ and critical droplet diameter $\left(\mathrm{d}_{c}\right)$ obtained by using the original Köhler equation with literature water activities (2th-3th columns), osmolality derived water activities (5th-6th columns) and derived from the simplified Köhler equation (7th-8th columns) for calcium chloride particles of different dry diameters $\left(\mathrm{d}_{d r y}\right)$.

Non-simplified Köhler equation Non-simplified Köhler equation Simplified Köhler $\mathrm{a}_{w}$ from literature equation ( $\mathrm{i}=3)$

\begin{tabular}{cccccccc}
\hline $\mathrm{d}_{d r y}(\mathrm{~nm})$ & $\mathrm{S}_{c}(\%)$ & $\mathrm{d}_{c}(\mathrm{~nm})$ & $\mathrm{d}_{c} / \mathrm{d}_{d r y}$ & $\mathrm{~S}_{c}(\%)$ & $\mathrm{d}_{c}(\mathrm{~nm})$ & $\mathrm{S}_{c}(\%)$ & $\mathrm{d}_{c}(\mathrm{~nm})$ \\
\hline 20 & 1.44 & 103 & 5.17 & 1.45 & 100 & 1.33 & 108 \\
40 & 0.513 & 284 & 7.11 & 0.511 & 284 & 0.470 & 306 \\
70 & 0.222 & 666 & 9.52 & 0.221 & 666 & 0.203 & 708 \\
100 & 0.130 & 1106 & 11.06 & 0.129 & 1106 & 0.119 & 1209 \\
\hline
\end{tabular}

G. Kiss and

H.-C. Hansson

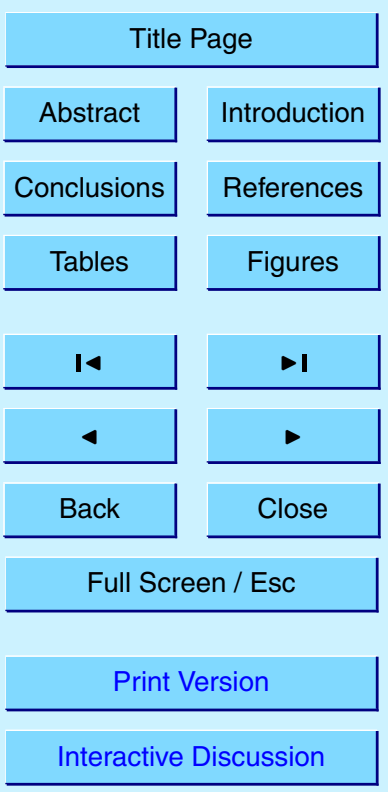




\section{ACPD}

4, 7667-7689, 2004

\section{Osmolality-derived activity in cloud modelling}

Table 4. The critical supersaturation $\left(\mathrm{S}_{c}\right)$ and critical droplet diameter $\left(\mathrm{d}_{c}\right)$ obtained by using G. Kiss and the original Köhler equation with literature water activities (2th-3th columns), osmolality derived water activities (5th-6th columns) and derived from the simplified Köhler equation (7th-8th columns) for sulphuric acid droplets of different initial diameters $\left(\mathrm{d}_{\text {initial }}\right)$.

\begin{tabular}{cccccccc}
\hline & \multicolumn{2}{c}{$\begin{array}{c}\text { Non-simplified Köhler equation } \\
\mathrm{a}_{w} \text { from literature }\end{array}$} & \multicolumn{2}{c}{$\begin{array}{c}\text { Non-simplified Köhler equation } \\
\mathrm{a}_{w} \text { from osmolality }\end{array}$} & \multicolumn{2}{c}{$\begin{array}{c}\text { Simplified Köhler } \\
\text { equation (i=3) }\end{array}$} \\
\hline $\mathrm{d}_{\text {initial }}(\mathrm{nm})$ & $\mathrm{S}_{c}(\%)$ & $\mathrm{d}_{c}(\mathrm{~nm})$ & $\mathrm{d}_{c} / \mathrm{d}_{\text {initial }}$ & $\mathrm{S}_{c}(\%)$ & $\mathrm{d}_{c}(\mathrm{~nm})$ & $\mathrm{S}_{c}(\%)$ & $\mathrm{d}_{c}(\mathrm{~nm})$ \\
\hline 20 & 1.66 & 87.8 & 4.39 & 1.64 & 86.8 & 1.35 & 106 \\
40 & 0.587 & 245 & 6.12 & 0.571 & 250 & 0.479 & 300 \\
70 & 0.253 & 565 & 8.07 & 0.245 & 576 & 0.207 & 695 \\
100 & 0.148 & 972 & 9.72 & 0.143 & 998 & 0.121 & 1186 \\
\hline
\end{tabular}

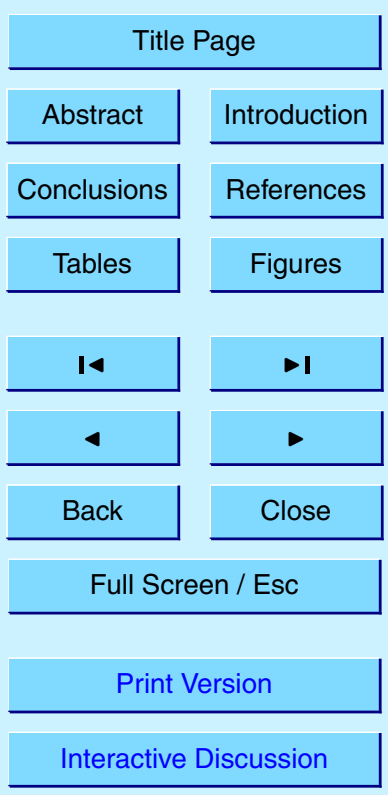




\section{ACPD}

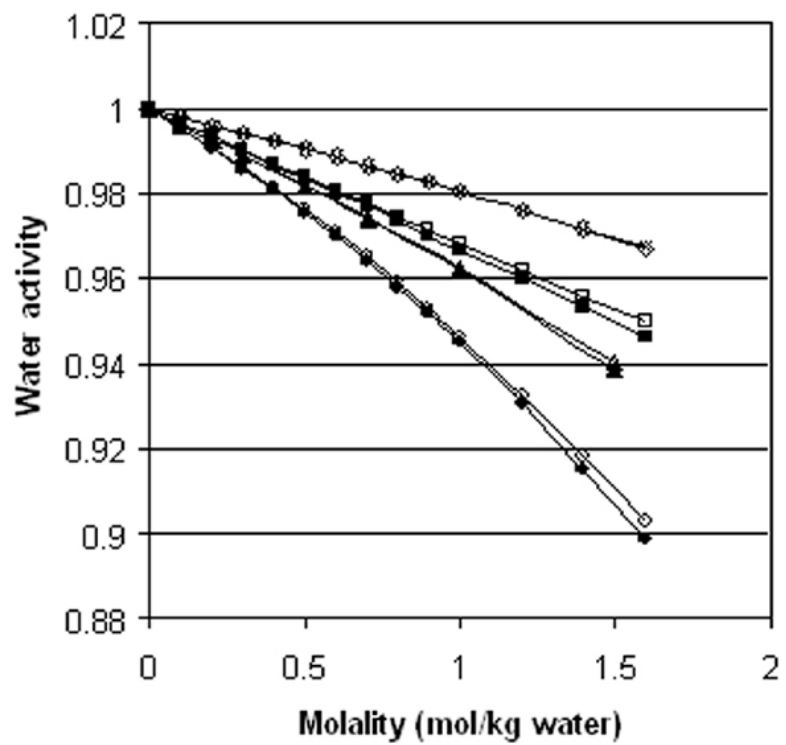

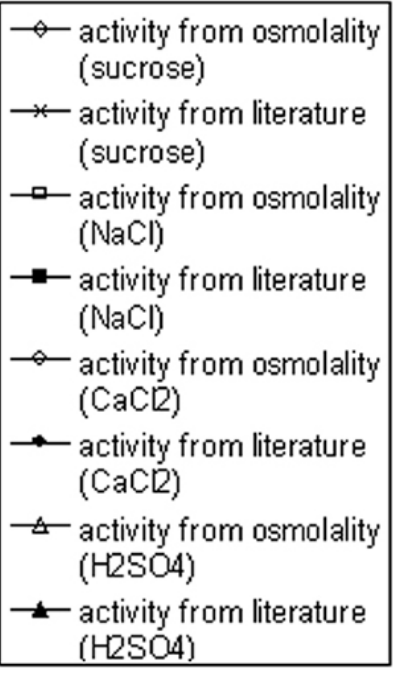

4, 7667-7689, 2004

\section{Osmolality-derived activity in cloud modelling}

G. Kiss and

H.-C. Hansson

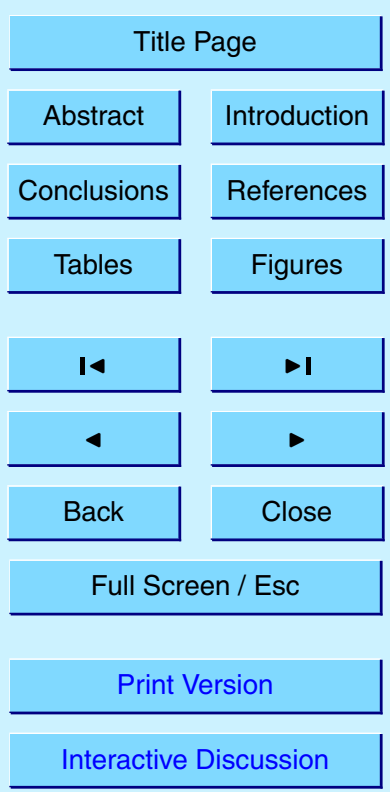

Fig. 1. Comparison of osmolality-derived water activity values with literature data for sucrose and three types of electrolytes. 


\section{ACPD}

4, 7667-7689, 2004
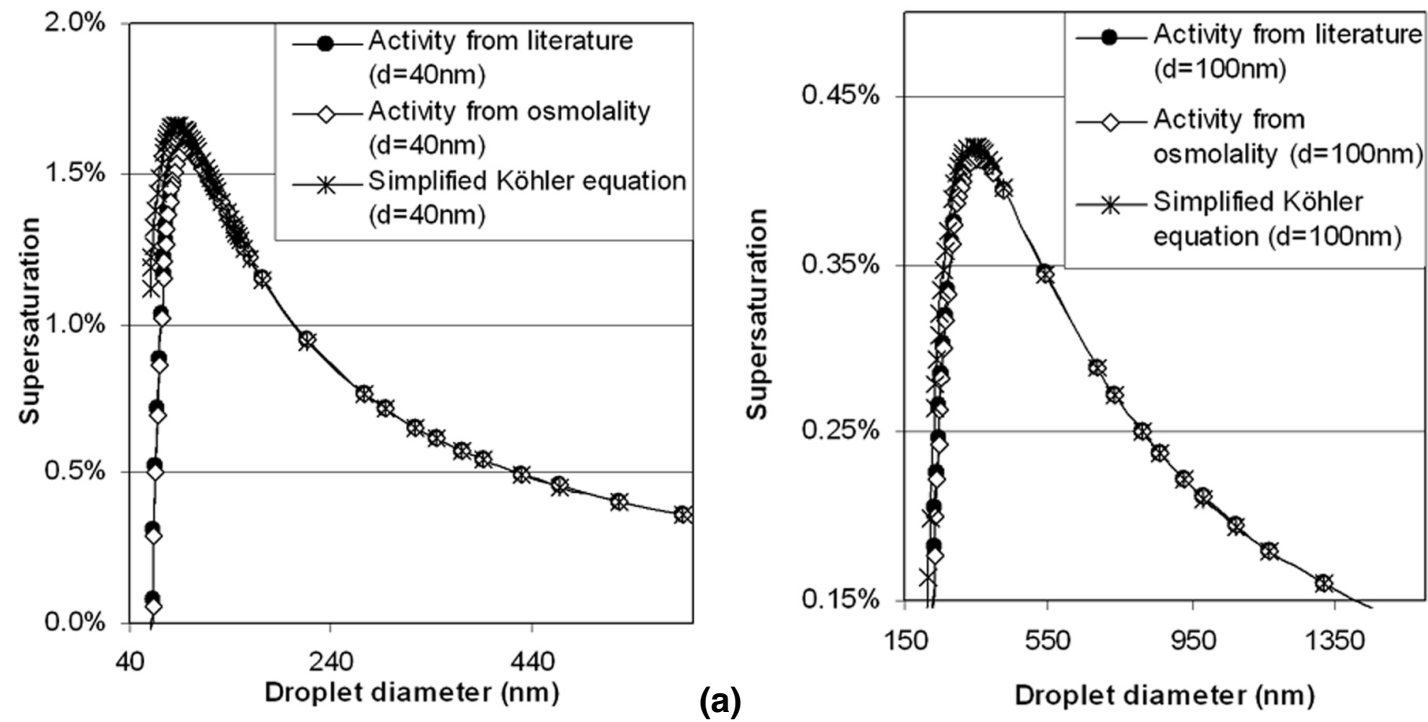

\section{Osmolality-derived activity in cloud modelling}

G. Kiss and

H.-C. Hansson

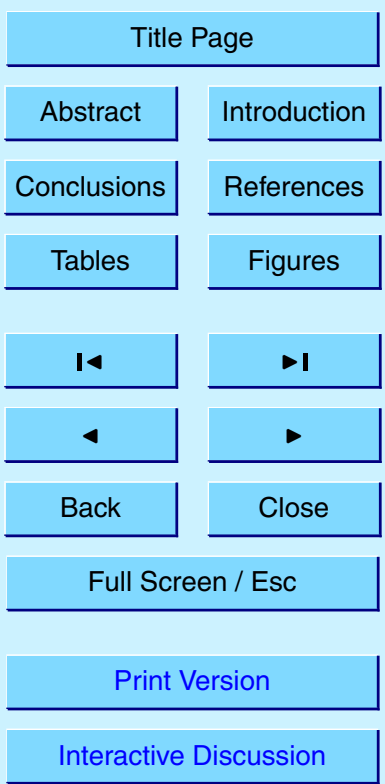

Fig. 2. Köhler curves obtained for a sucrose particle of (a) $d_{d r y}=40 \mathrm{~nm}$ and (b) $d_{d r y}=100 \mathrm{~nm}$ substituting literature water activity values or osmolality derived water activity values into the original Köhler equation. The curves obtained by using the simplified Köhler equation assuming van't Hoff factor of 1 are also shown. 


\section{ACPD}
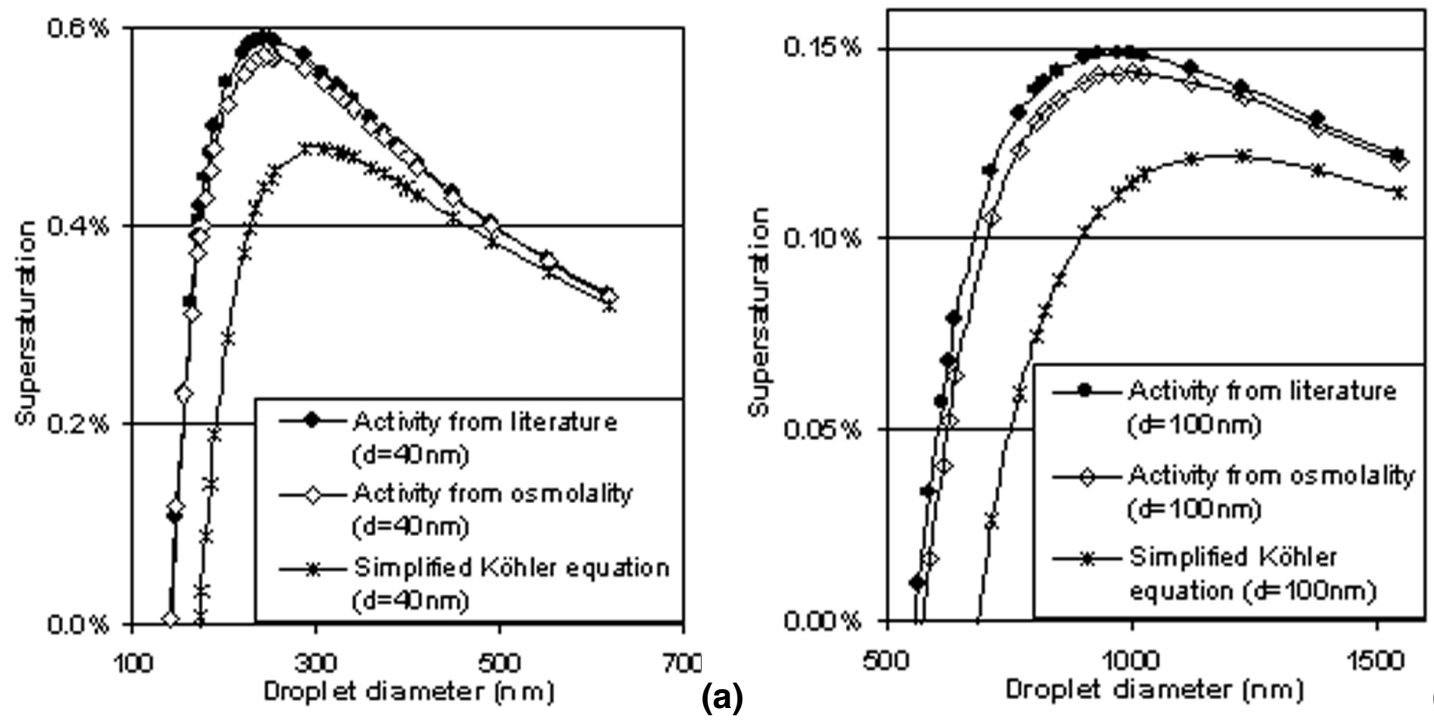

4, 7667-7689, 2004

\section{Osmolality-derived activity in cloud modelling}

G. Kiss and

H.-C. Hansson

Fig. 3. Köhler curves obtained for a sulphuric acid droplet of (a) $d_{\text {initial }}=40 \mathrm{~nm}$ and (b) $\mathrm{d}_{\text {initial }}=100 \mathrm{~nm}$ substituting literature water activity values or osmolality derived water activity values into the original Köhler equation. The curves obtained by using the simplified Köhler equation assuming van't Hoff factor of 3 are also shown.

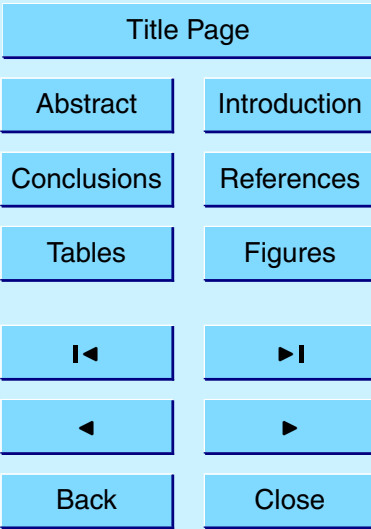

Full Screen / Esc

Print Version

Interactive Discussion 


\section{ACPD}
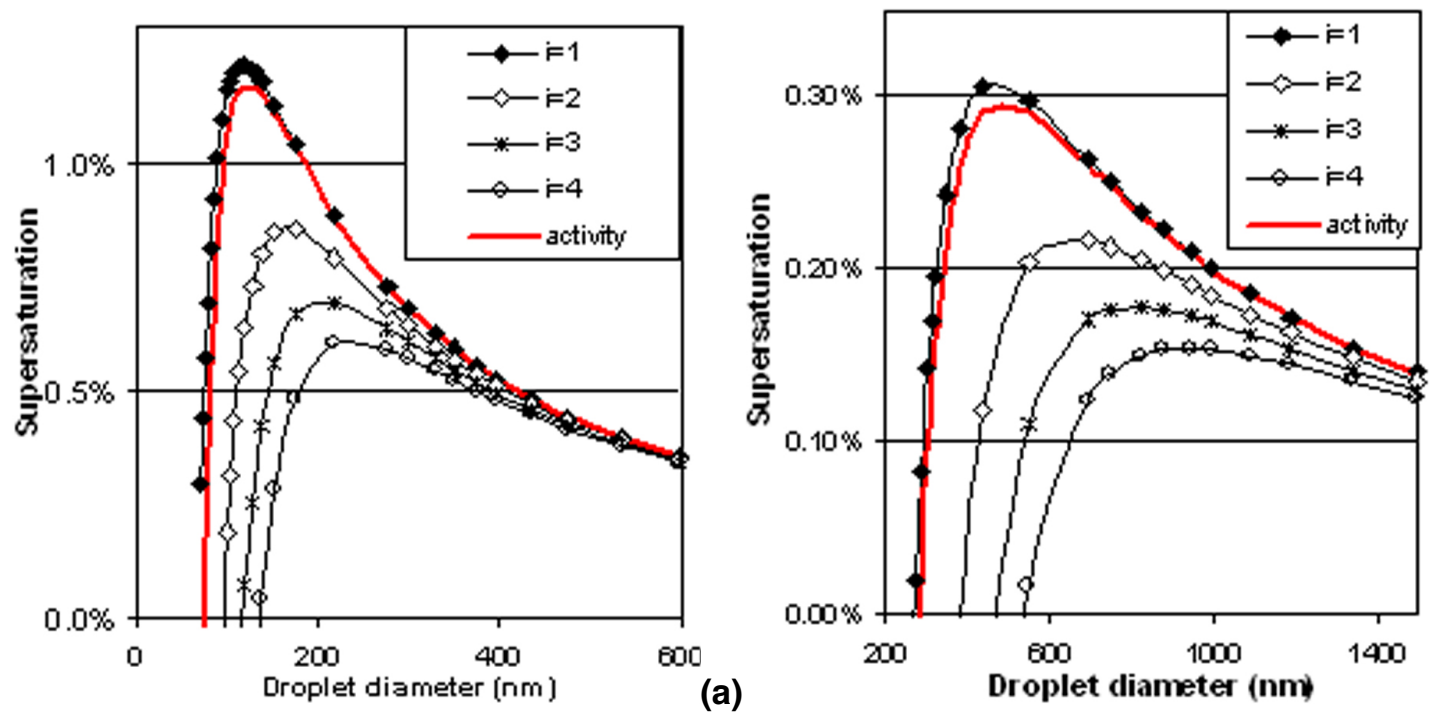

(b)
4, 7667-7689, 2004

Osmolality-derived activity in cloud modelling

G. Kiss and

H.-C. Hansson

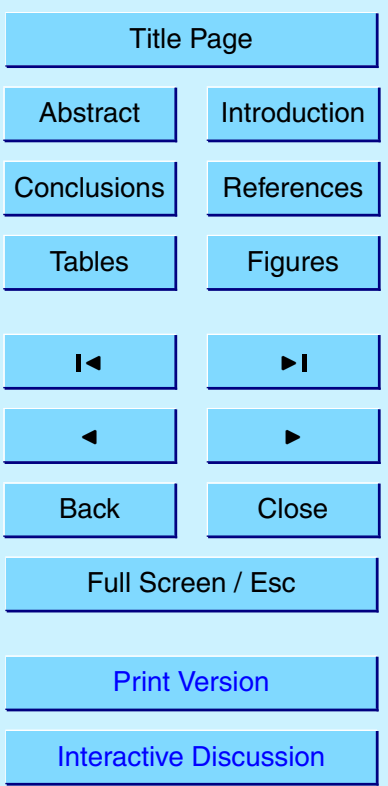

Fig. 4. Köhler curves obtained for a citric acid particle of (a) $d_{d r y}=40 \mathrm{~nm}$ and (b) $d_{d r y}=100 \mathrm{~nm}$ using the Simplified Köhler equation and assuming van't Hoff factors of 1, 2, 3 and 4 . The red lines without marker show the curves obtained with the original Köhler equation by using osmolality derived water activity values. 